\title{
Herd and within-herd BoHV-1 prevalence among Irish beef herds submitting bulls for entry to a performance testing station
}

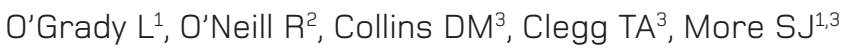

${ }^{1}$ Section of Herd and Veterinary Public Health, School of Agriculture, Food Science and Veterinary Medicine, University College Dublin, Belfield, Dublin 4, Ireland

${ }^{2}$ Central Veterinary Research Laboratory, Virology Division, Backweston Campus, Young's Cross, Celbridge, Co. Kildare, Ireland

${ }^{3}$ Centre for Veterinary Epidemiology and Risk Analysis, School of Agriculture, Food Science and Veterinary Medicine, University College Dublin, Belfield, Dublin 4, Ireland

\section{ABSTRACT}

Infectious bovine rhinotracheitis (IBR), caused by bovine herpes virus 1 (BoHV-1), may result in various clinical consequences, including severe respiratory disease and conjunctivitis, venereal disease and reduced reproductive performance and abortion. This paper presents the serosurveillance findings from an intake of bulls into a performance testing station in Ireland during November 2007 . The herd and within-herd BoHV-1 prevalence in 53 Irish beef herds and the risk factors for infection in these herds were determined, among bulls entering a beef performance testing station in Ireland. BoHV-1 status was determined for 41 herds, of which 30 (73.2\%) herds were infected and the mean within-herd BoHV-1 prevalence was $28( \pm 20) \%$. Multivariate exact logistic modelling revealed increasing numbers of contiguous herds and decreasing percentage of males within the herd as significant risk factors associated with infected herds. These findings highlight the high prevalence of BoHV-1 infection in those Irish beef herds that submitted bulls to this performance testing station, and raise concerns regarding IBR control nationally.

KEYWORDS: beef herds, BoHV-1, bovine herpes virus 1, disease freedom, IBR, infectious bovine rhinotracheitis, Ireland, prevalence

\section{CORRESPONDING AUTHOR:}

Luke O'Grady, Section of Herd and Veterinary Public Health, School of Agriculture, Food Science and Veterinary Medicine, University College Dublin, Belfield, Dublin 4

Email: luke.ogrady@ucd.ie

Tel.: +3531716 6075

Fax: +3531716 6005

\section{INTRODUCTION}

Infectious Bovine Rhinotracheitis (IBR), caused by bovine herpes virus 1 (BoHV-1), may result in various clinical consequences, including severe respiratory disease, venereal disease with reduced reproductive performance and abortion. Like other herpes viruses, BoHV-1 also results in lifelong latent infections. The virus may be spread within cattle populations via contact, aerosol, fomites and via infected semen, ova or embryos (Muylkens et al. 2007).

There are substantial economic consequences associated with respiratory disease as a result of BoHV-1 (Castrucci et al. 2000). In addition, BoHV-1-free status is an important issue in the international trade of live animals and some animal products. As an international standard, all semen used in artificial insemination must be sourced 
from BoHV-1 seronegative bulls (de Ruigh et al. 2006). Furthermore, BoHV-1 has been eradicated from a number of countries within Europe (including Austria, Denmark, Finland, several Italian provinces, Norway, Sweden and Switzerland) (Ackermann and Engels 2006). In some other countries (France, Germany, the Netherlands), eradication programmes are in place (Ackermann and Engels 2006). Eradication strategies have been based on a foundation of improved herd and regional bio-security, in conjunction with a test and slaughter policy (European Food Safety Authority 2006). BoHV-1 status has emerged as a barrier to withincommunity trade, with EU directives 64/432, 88/407 and 93/60 (Anon 1964; Anon 1988; Anon 1993) allowing member states to stipulate requirements to be met for the importation of cattle, semen and embryos (Noordegraaf et al. 2000). In some countries where infection is endemic, the use of marker vaccination (gene deleted vaccines) has been introduced to reduce herd prevalence, whilst still allowing the differentiation between wild virus exposure and vaccination. In Ireland, only the use of marker vaccines is permitted, but there is currently no national BoHV-1 control programme in place.

In early 2007, an outbreak of clinical IBR occurred at a beef bull performance testing station in Ireland. At this performance testing station, the best beef bulls would be identified for future use as artificial insemination (AI) sires. The outbreak resulted in substantial economic losses, including a loss of potential for genetic gain within the Irish beef sector. As a result, the facility was temporarily closed and biosecurity measures were revised. From late 2007, a number of new measures were introduced including prior to (farm-of-origin serosurveillance, pre-entry isolation) and following (testing station biosecurity) entry. Results from pre-entry serosurveillance were used to assess infection risk in each herd-of-origin (source herd). This paper presents the serosurveillance findings from the bull intake to this testing station in November 2007. The objectives of this study were:

(i) To determine the herd and within-herd BoHV-1 prevalence of all source herds supplying bulls to a performance testing station;

(ii) To identify risk factors associated with BoHV-1 infection in these herds; and,

(iii) To highlight the challenges faced in achieving freedom from BoHV-1 infection among bulls entering the test station.

\section{MATERIALS AND METHODS}

\section{STUDY FARMS}

The study farms include all Irish farms ( $n=53$ farms) that sought to submit bulls for entry to a bull performance testing station during the November 2007 bull intake. These herds each contained at least one high genetic merit bull, 6-9 months of age, as identified based on an Irish economic breeding index (Amer et al. 2001; Veerkamp et al. 2002) and physical inspection. Furthermore, each herd keeper had agreed to a serological assessment of the health status of their herd.

\section{SAMPLE COLLECTION}

The total sample size for each farm was determined based on calculations to substantiate freedom from infection (Cameron and Baldock 1998). It was assumed if infection were present, the minimum expected prevalence would be $10 \%$. The test characteristics used in the sample size calculations were a test sensitivity and specificity of $99 \%$ and $99.7 \%$, respectively.

During November 2007, local veterinarians conducted all sampling on the study farms. A clotted serum sample was obtained from each candidate bull. Veterinarians were asked to collect further samples from each herd, drawing from the following groups of animals in decreasing order of preference:

(i) The dam of each candidate bull;

(ii) Those in very close contact with the candidate bull (up to, but no greater than $40 \%$ of samples collected);

(iii) Other animals, in the opinion of the veterinarian, mostlikely to be infected with BoHV-1, including older animals, animals during the last 12 months that were in contact with shows, marts and animals from neighbouring farms (up to, but no greater than $40 \%$ of samples collected); and,

(iv) Other animals in the herd, starting with those that might have had some level of contact with the candidate bull and its dam (the remainder of samples). This strategy was devised to maximise confidence in the chances of establishing freedom from BoHV-1 infection.

\section{LABORATORY TESTING}

Clotted serum samples were sent to the Central Veterinary Research Laboratory (Department of Agriculture, Fisheries and Food [DAFF], Celbridge, Co. Kildare, Ireland). All samples were tested in duplicate for the presence of BoHV-1 antibodies using a commercial gB IBR ELISA (HerdChek® Infectious Bovine Rhinotracheitis [IBR]/ Bovine Herpesvirus-1 [BHV-1] gB Antibody ELISA Test Kit, IDEXX Europe BV, The Netherlands). The sensitivity and specificity of this assay was previously estimated at $99 \%$ and $99.7 \%$, respectively (Kramps et al. 1994). In those herds where gB positive animals were identified, up to 12 gB positive samples were retested using a commercial gE ELISA (HerdChek® Infectious Bovine Rhinotracheitis [IBR]/Bovine Herpesvirus-1 [BHV-1] gE Antibody ELISA Test Kit, IDEXX Europe BV, The Netherlands) to differentiate vaccination and exposure to wild type virus. The gE ELISA is reported to have a lower analytical sensitivity than the gB ELISA (Kramps et al. 2004). Serological test results were classified as either positive or negative. A severe interpretation was applied and inconclusive ELISA results were reclassified as positive.

\section{DATA COLLECTION}

The field veterinarian collected a range of data, including herd number, herd IBR vaccination status, animal identification and animal status (candidate bull, dam, other animal from the herd). Using DAFF's Animal Identification and Movement System database, the total number of animals present in each study herd on the date of sample 
collection was determined, and data about each of these animals, including date of birth, breed, sex and movements (date of entry into herd, if applicable). Using this database, all inward cattle movements were identified, either from marts or private premises, into each study herd from January 1, 2007 until the date of sample collection. The number of herds contiguous to each of the sample farms was calculated using ESRI Arcview 3.2 (Redlands, California, USA), based on 2007 data in DAFF's Land Parcel Identification Scheme (LPIS). These latter data were available for 51 of the study herds.

\section{DATA MANAGEMENT AND ANALYSIS}

Data were managed in Microsoft Excel and Access (Microsoft Corporation, Redmond, WA, USA), and analysed using Stata ${ }^{\circledR}$ version 10 (Stata Corp, College Station, TX, USA), Freecalc version 2 and Survey Toolbox version 1.04 (AusVet Animal Health Services, Australia) and ESRI Arcview 3.2 (Redlands, California, USA). Paper-based farm and serological data were manually entered in Excel, then managed in Access as a herd and animal-level database. The location of each study herd was mapped using Arcview, based on the centroid of the largest fragment of each farm. For the two herds without LPIS data, the centroid of the relevant district electoral division was used to represent farm location.

Herds with at least one animal with a gB positive, gE negative result were classified as vaccinated or any herd with a history of vaccination, were not considered in further analyses.

The probability of freedom from infection was determined using Freecalc. Using the sample results from each herd, we calculated the probabilities of observing such a result under the null (that infection is present at a prevalence of $\geq 10 \%$ ) and alternative (that the population is free from infection, prevalence $=0 \%$ ) hypotheses (Cameron and Baldock 1998). A minimum within-herd prevalence of $10 \%$ or greater was assumed if infection was present, a test sensitivity and specificity of $99 \%$ and $99.7 \%$, respectively was used, and type I and II errors defined at 0.05. Using these criteria, herds were classified as infection free if there was sufficient confidence to rejecting the null hypothesis ( $p<0.05)$, but not to reject the alternative hypothesis $(p>0.05)$. Infected herds were classified as based on there being sufficient confidence to rejecting the alternative hypothesis $(p<0.05)$ but not to reject the null hypothesis $(p>0.05)$. In some herds, where insufficient samples were collected, and no conclusion about infection status could be made, this is shown as 'inadequate numbers sampled'. For those herds classified as infected, the authors estimated true within-herd prevalence using the true prevalence function of Survey Toolbox.

Univariable and multivariable analyses were conducted on the 41 herds classified as either infected or non-infected, using exact logistic regression (stata exlogistic) and the herd as the unit of interest. The outcome of interest was herd infection status. A number of independent variables were considered including herd size, average herd age, percentage of herd male (MALE), percentage of herd pure bred, percentage of herd home bred, closed herd since the beginning of 2007, number of contiguous herds (CONTIG), number of bought-in cattle originating from farms since the beginning of 2007 and the number of bought-in cattle originating from marts since the beginning of 2007 (MART07). Variables were treated as continuous if a plot of the log odds of a herd being infected against the midpoints of categorical variables (built using the quartiles of the continuous data) was approximately linear. The variables MARTO7, CONTIG and MALE all appeared to be linearly related to the log odds and were kept as continuous variables. The other remaining independent variables were categorised prior to analysis, after developing histograms and choosing either clearly defined categories or divisions into quartiles based on biological plausibility. To limit the number of predictors in the model, univariate screening was performed so that variables with $p<0.20$ at the univariate level became candidates for the model. A backward-selection procedure was then used based on a mid P-value of 0.05. Finally, terms that were excluded at the initial screening stage for inclusion were tested in the final model $(p<0.05)$. No interaction terms were considered in the model because of the small sample size.

\section{RESULTS}

\section{DESCRIPTIVE ANALYSIS}

A total of 1,462 serum samples (73 candidate bulls, 72 dams, 1,317 cohort animals) were collected from 53 study herds. Six herds (179 samples) had either a history or evidence of vaccination (specific vaccination details were not available). Among the 47 herds (1,283 samples including 65 candidate bulls, 64 dams, 1,154 cohort animals) that did not vaccinate, 257 samples (20.0\%) were gB positive, including four (6.2\%) candidate bulls, 19 (29.7\%) dams and 234 (20.3\%) cohort animals. The agespecific BoHV-1 prevalence and number of animals in each age category among the 1,283 cattle from the 47 nonvaccinated herds is presented in Figure 1.

Descriptive information about the 53 study herds is presented in Table 1.

\section{INFECTION STATUS AND WITHIN-HERD PREVALENCE}

Among the 53 study herds, 30 (57\%) were infected, 11 (21\%) were not and infection status of 12 (23\%) herds was

Table 1. Descriptive information about the 53 study herds

\begin{tabular}{|l|l|l|l|l|}
\hline Variable & Range & $25 \%$ Quartile & Median & $75 \%$ Quartile \\
\hline Herd size & $5-320$ & 33 & 55 & 104 \\
\hline $\begin{array}{l}\text { Number sampled } \\
\text { per herd }\end{array}$ & $5-50$ & 20 & 29 & 36 \\
\hline $\begin{array}{l}\text { Number of animals } \\
\text { bought in 2007 }\end{array}$ & $0-51$ & 1 & 3 & 12 \\
\hline $\begin{array}{l}\text { Number of } \\
\text { contiguous herds }\end{array}$ & $2-50$ & 8 & 12 & 16.5 \\
\hline
\end{tabular}


not determined, either due to vaccination (six herds) or an insufficient number of animals sampled (six herds). The geographic distribution of these herds, by infection status, is presented in Figure 2. Among herds with known infection status, herd BoHV-1 prevalence was $73.2 \%$. The mean within-herd prevalence in the 30 infected herds was $28 \%$ (SD 20 \%) (Figure 3).

\section{MULTIVARIABLE ANALYSIS}

Unconditional associations between infection status and either categorical or continuous independent variables are presented in Table $\mathbf{2}$ and Table 3, respectively. In the final exact logistic regression model (Table 4), MALE and CONTIG were significantly associated with herd infection status.

The effect of these risk factors was not great, as the 95\% confidence intervals for the odds ratios of both of these risk factors approach one (Table 4). Also for the risk factor CONTIG the removal of the maximum outlier from the data resulted in a p value of 0.053 and an odds ratio of 1.12 .

\section{DISCUSSION}

\section{HERD AND WITHIN-HERD PREVALENCE}

BoHV-1 infection is prevalent in Irish cattle herds. In this study, among herds with known infection status, herd BoHV-1 prevalence was 73.2\%. Furthermore, infected herds were located throughout the country (Figure 2). Such information from Ireland has not previously been reported (Ackermann and Engels 2006). These results concur with levels of infection reported from other countries prior to the establishment of national control programmes, including Engels 2006). For example, a herd prevalence of $67 \%$ (Boelaert et al. 2000) and 97\% (Solis-Calderon et al. 2003) was reported from Belgium and Mexico, respectively.

\section{SAMPLING STRATEGY}

The study farms are likely to be representative of beef herds in Ireland from which high genetic merit animals are sourced. Within such herds, BoHV-1 risks may be increased as a result of practices such as bull showing. However, 54\% of these herds contained less than $70 \%$ purebred animals, indicating that these herds may have Belgium, Italy, Spain and the Netherlands (Ackermann and

Table 2. Unconditional associations between categorical independent variables and infection status of 41 study herds in Ireland during November 2007

\begin{tabular}{|c|c|c|c|c|}
\hline \multirow[b]{2}{*}{ Variable } & \multicolumn{4}{|c|}{ Herd infection status } \\
\hline & $\begin{array}{l}\text { Total (\%) } \\
(n=41 \\
\text { herds) }\end{array}$ & $\begin{array}{l}\text { Non- } \\
\text { infected } \\
(\%)(n=11 \\
\text { herds) }\end{array}$ & $\begin{array}{l}\text { Infected } \\
(\%) \\
(n=30 \\
\text { herds) }\end{array}$ & P-value \\
\hline
\end{tabular}

\section{Herd size}

\begin{tabular}{|l|l|l|l|r|}
\hline 1) $4-32$ animals & 27 & 18 & 30 & \\
\hline 2) 33-55 animals & 24 & 45 & 17 & \multirow{2}{*}{0.2256} \\
\hline 3) $56-88$ animals & 24 & 27 & 23 & 30 \\
\hline 4) $89-320$ animals & 24 & 9 & & \\
\hline
\end{tabular}

Number of farm-bought cattle during 2007

\begin{tabular}{|c|c|c|}
\hline 1) 0 animals & 37 & 45 \\
\hline 2) $1-2$ animals & 22 & 18 \\
\hline 3) 3-5 animals & 22 & 9 \\
\hline 4) 6-22 animals & 20 & 27 \\
\hline
\end{tabular}

Closed herd '07

\begin{tabular}{|l|l|l|l|l|}
\hline Yes & 20 & 27 & 17 & 0.6582 \\
\hline No & 80 & 73 & 83 & \\
\hline
\end{tabular}

Percentage purebred

\begin{tabular}{|l|l|l|l|l|}
\hline 1) $0-50 \%$ & 37 & 27 & 40 & \\
\hline 2) $51-90 \%$ & 29 & 27 & 30 & 0.6795 \\
\hline 3) $91-100 \%$ & 34 & 45 & 30 & \\
\hline
\end{tabular}

Average herd age

\begin{tabular}{|l|l|l|l|l|}
\hline 1$) 1.77-3.01$ years & 27 & 27 & 27 & \\
\hline 2) $3.02-3.40$ years & 24 & 18 & 27 & 0.2612 \\
\hline 3) $3.41-3.75$ years & 24 & 45 & 17 & 30 \\
\hline 4) $3.76-4.98$ years & 24 & 9 & & \\
\hline Percentage homebred & 63 & 45 & 70 & \\
\hline 1) $15-79 \%$ & 37 & 55 & 30 & 0.2720 \\
\hline 2) $80-100 \%$ & & & & \\
\hline
\end{tabular}

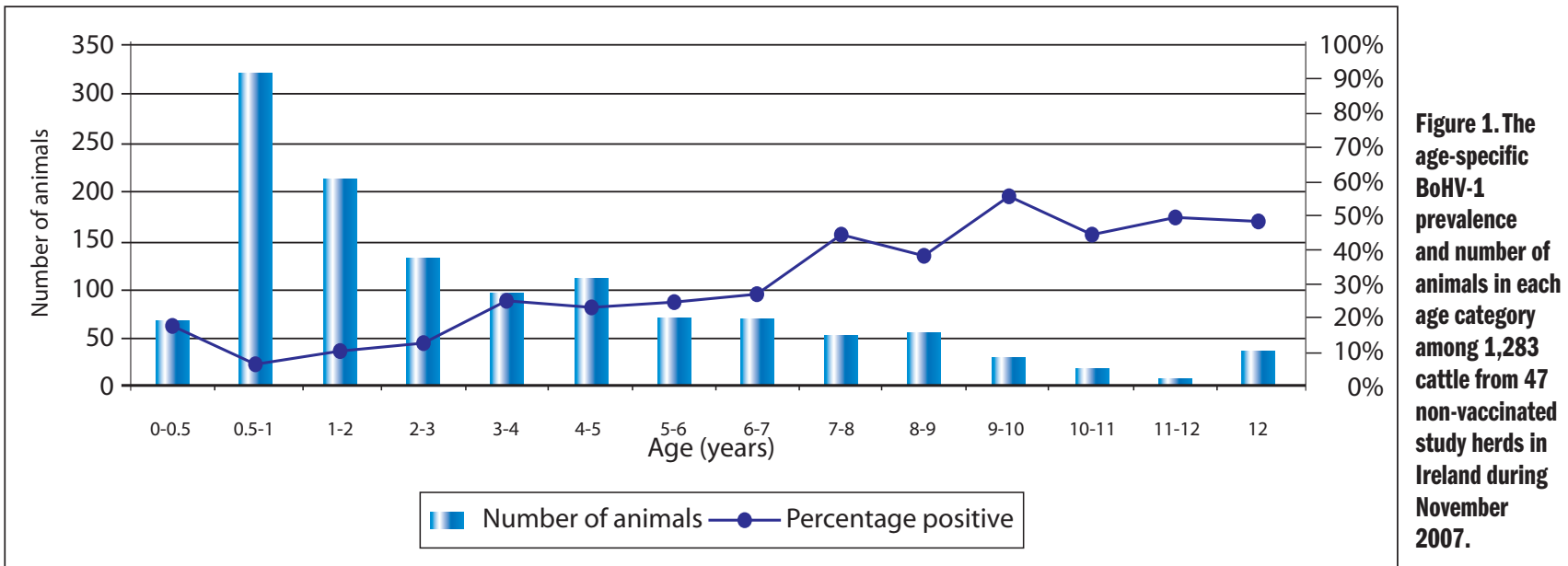


Table 3. Unconditional associations between continuous independent variables and infection status of $\mathbf{4 1}$ study herds in Ireland during November 2007

\begin{tabular}{|l|l|l|l|l|l|l|} 
& \multicolumn{2}{|l|}{$\begin{array}{l}\text { Non-infected } \\
\text { (n=11) }\end{array}$} & \multicolumn{3}{l|}{ Infected (n=30) } & \\
\hline Variable & Median & Range & Median & Range & P-value \\
\hline $\begin{array}{l}\text { Number of mart-bought } \\
\text { animals during 2007 }\end{array}$ & 0 & $0-5$ & 2 & $0-21$ & 0.066 \\
\hline $\begin{array}{l}\text { Number of contiguous } \\
\text { herds }\end{array}$ & 11 & $3-16$ & 12 & $3-50$ & 0.067 \\
\hline Percentage male (\%) & 25 & $13-40$ & 23 & $6-34$ & 0.072 \\
\hline
\end{tabular}

Table 4. Variables conditionally associated with herd BoHV-1 infection status of 41 study herds in Ireland during November 2007, based on results from an exact logistic regression model

\begin{tabular}{ll|l|l|l}
\multirow{2}{*}{ Variable } & \multirow{2}{*}{ Odds ratio } & \multicolumn{2}{|c|}{$95 \%$ Confidence interval } & \multirow{2}{*}{ P-value } \\
\cline { 3 - 5 } & Lower & Upper & P- \\
\hline $\begin{array}{l}\text { Percentage of } \\
\text { herd male }\end{array}$ & 0.88 & 0.77 & 1.00 & 0.040 \\
\hline $\begin{array}{l}\text { Contiguous } \\
\text { herds }\end{array}$ & 1.13 & 1.01 & 1.33 & 0.042 \\
\hline
\end{tabular}

a mixture of enterprises. Therefore, it is likely that they are also representative of commercial beef enterprises. In this serosurvey, the sampling strategy and severe test interpretation placed on inconclusive results was designed to maximise the detection of BoHV-1 infection within herds supplying this bull performance station. This provided confidence in the assessment of herd-level freedom from infection, but may have resulted in possible over-estimation of within-herd prevalence. The legal use of non-marker IBR vaccines ceased at the end of 2004. Therefore, it is possible that some positive serology in older cattle was due to previous (non-marker) vaccination, rather than natural infection. This effect will also contribute to an overestimation of within-herd prevalence estimates. Although information was sought regarding vaccination history, the authors acknowledge that accurate data about bought-in animals was not always available. This possible source of error may have contributed to the age related trends seen in Figure 1.

The classification of herd freedom was based on the assumption that within-herd prevalence would be at least $10 \%$, if infection were present, drawing on an understanding of BoHV-1 infection dynamics and of withinherd transmission of infection following introduction. This is consistent with current international thinking on the issue of disease freedom (Cameron and Baldock 1998; Martin et al. 2007a; Martin et al. 2007b). Note, however, that a single seropositive animal was detected in four of the 11 herds that were subsequently classified as free from infection. In each of these herds, the 95\% confidence interval for true withinherd prevalence was less than $10 \%$. The authors accept that these may be true positive results, e.g, the minimum assumed prevalence was too high, such as in the case of a seropositive animal having been recently-infected, recently-introduced or a single latent BoHV-1 carrier. If this were true, herd prevalence would in fact be $83.0 \%$ (34 positive herds/ 41 herds where infection status could be assessed). Therefore, these herds would also be at greater infection risk, with implications for safe entry of bulls from these herds into this testing station. Alternatively, these animals may have returned a false positive result, noting that the specificity of the gB ELISA is not perfect (Kramps et al. 1994).

\section{MULTIVARIABLE RISK FACTOR ANALYSIS}

Two factors were significantly associated with an increased BoHV-1 risk in herds, including an increasing number of contiguous herds and a decreasing percentage of male animals within a study herd. The former risk factor could reasonably be linked with levels of biosecurity on the study farms, given that infection risk is likely to be increased with an increasing number of infected neighbouring herds. In previous studies, Boelaert et al. (2005) and van Schaik et al. (1998) each identified animal purchases as a significant risk to biosecurity. In the current study, the number of

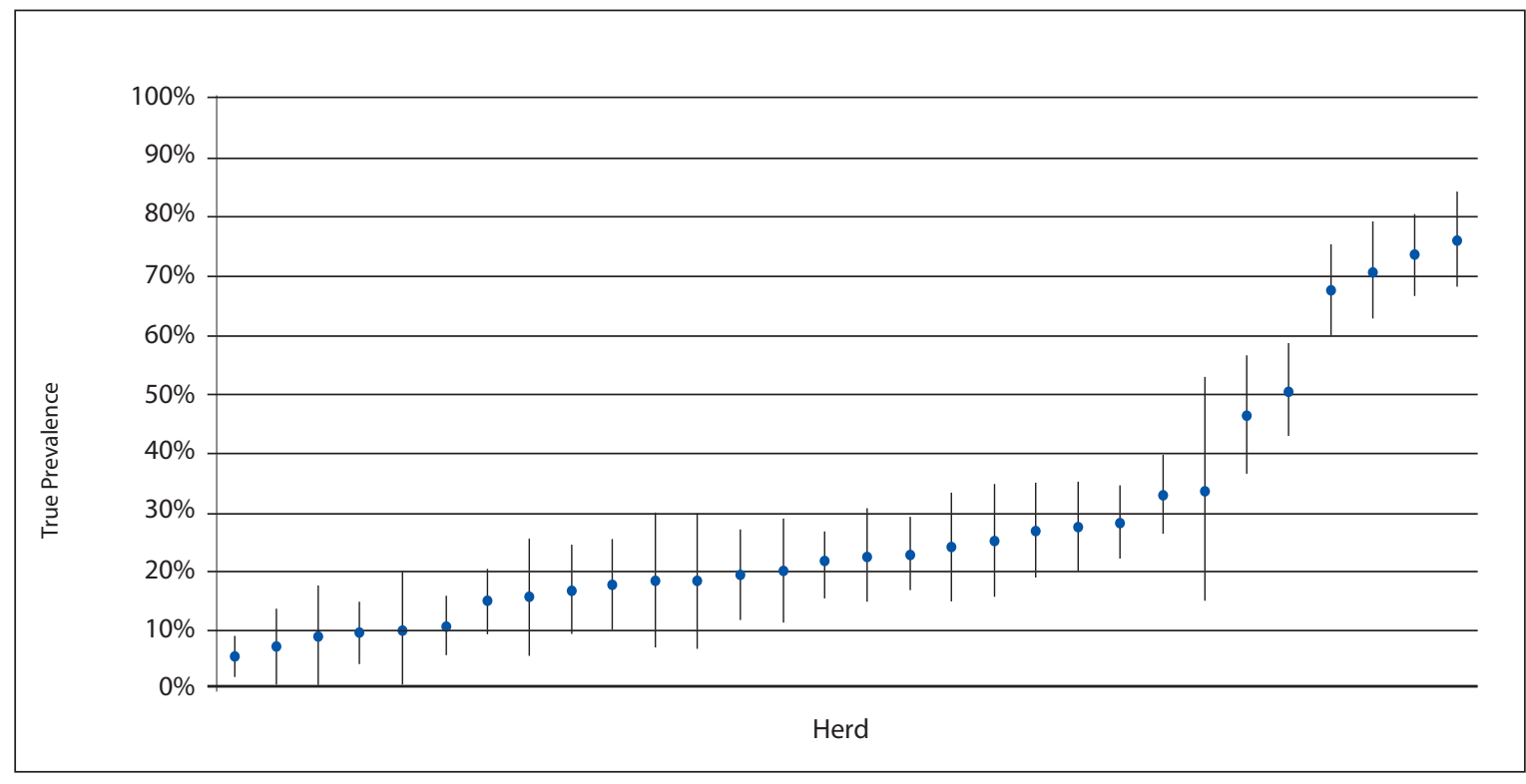

Figure 3. The within-herd true BoHV-1 prevalence for 30 infected study herds in Ireland during November 2007. The prevalence estimate and $95 \%$ confidence limits for each herd are represented by a dot and vertical line, respectively. 
purchases from markets was initially considered, but was not found to be significant in the final model. This may be due to the relatively small number of herds sampled. Furthermore, animals with BoHV-1 infection are seropositive for life; therefore, previously exposed animals may mask the impact of herd purchases on the overall herd status. Boelaert et al. (2005) also found conflicting results regarding the effect of sex on herd status. These authors found that animal infection risk increased with increasing age. In the current study, a similar age-related trend was noted (Figure 1); however, this was not significant. In Irish beef herds, older animals are more likely to be female, and therefore, a decreasing percentage of male animals may be a proxy for increasing age.

\section{IMPLICATIONS FOR BULL TESTING}

This study has highlighted the significant challenge faced by this Irish bull performance testing station in the selection and production of high quality sires for Al. Specifically, there are substantial risks in creating an 'island' of BoHV-1

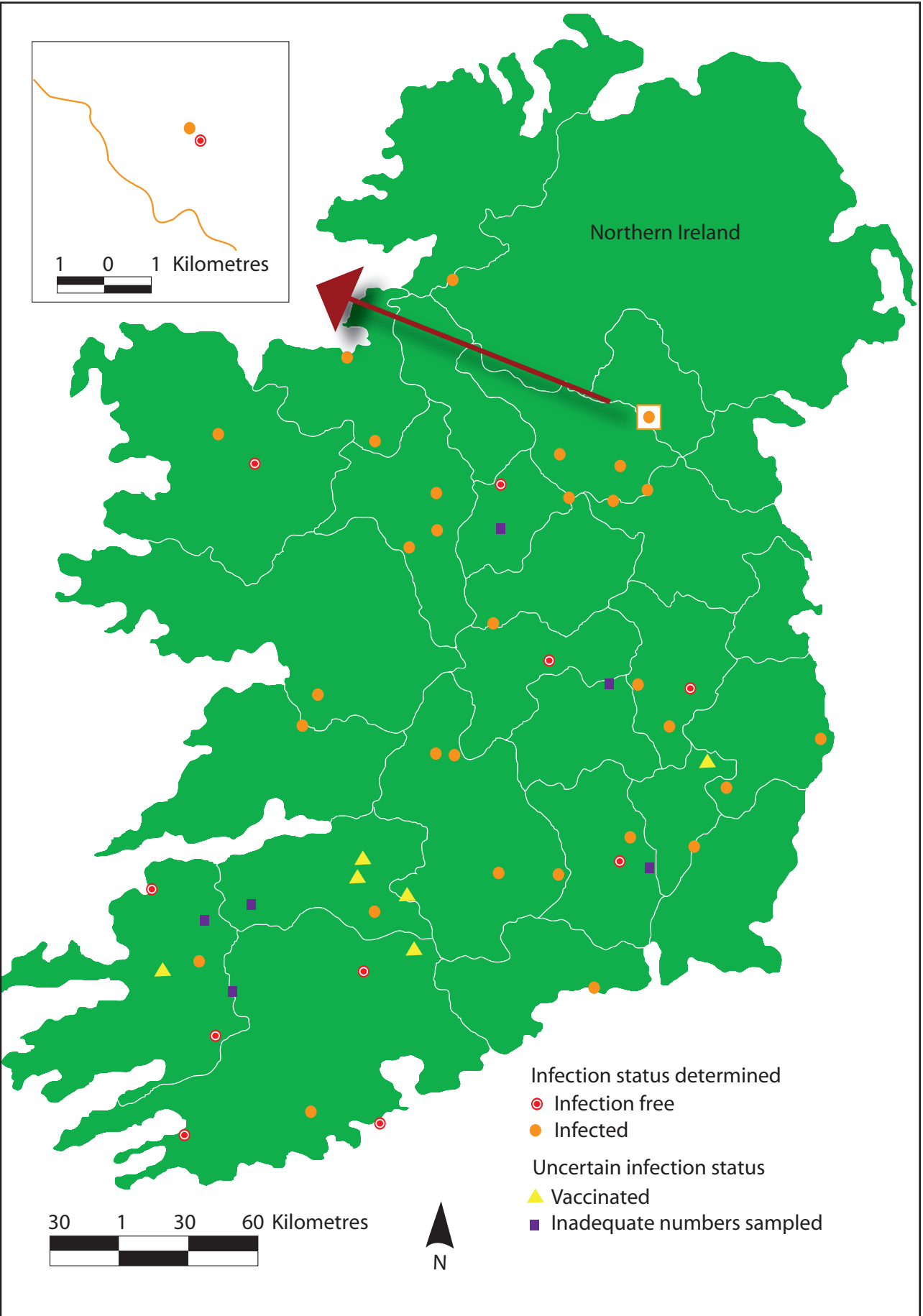

Figure 2. Geographic distribution of the 53 study herds, by BoHV-1 infection status.

freedom within a sea of endemic BoHV-1 infection. BoHV1 incursions lead to substantial economic consequences, both to bull owners and to testing organisations. It will be very difficult to avoid future outbreaks in centres such as this, in the absence of any national initiative to control BoHV-1 infection in Ireland.

\section{CONCLUSIONS}

BoHV-1 infection is prevalent and widespread through the Irish cattle population surveyed in this study. This population is likely to be representative in nature for much of the national herd with respect to disease status. This study highlights some of the challenges faced when conducting national disease surveillance. For example, although excellent diagnostic facilities are available for sample testing, the collection and correlation of farm and animal data is cumbersome and highly labour intensive. Future investment in surveillance will also be needed if national control programmes are to be established. A number of countries in Europe have moved, or are moving, towards freedom from infection (European Food Safety Authority 2006). Any attempts at BoHV-1 control are likely to be problematic, given the endemic nature of BoHV-1 infection in Ireland. This will have important implications for Ireland, given the importance of live cattle export to Europe and international standards in semen production. 


\section{REFERENCES}

Ackermann M and Engels M (2006) Pro and contra IBR-eradication. Veterinary Microbiology 113, 293-302.

Amer PR, Simm, G, Keane, MG et al. (2001) Breeding objectives for cattle in Ireland. Livestock Production Science 67, 223239.

Anon. (1964) Council Directive of 26 June 1964 on animal health problems affecting intra-Community trade in bovine animals and swine (64/432/EEC). Official Journal of the European Communities L121,: 1977-2012. July 29, 1964 (including successive amendments and corrigenda). [Online] Available from: http://eur-lex.europa.eu/LexUriServ/site/ en/consleg/1964/L/01964L0432-20070105-en.pdf (consolidated text). [Accessed on 02 July 2008].

Anon. (1988) Council Directive 88/407/EEC of 14 June 1988 laying down the animal health requirements applicable to intra-c Community trade in and imports of deep-frozen semen of domestic animals of the bovine species. Official Journal of the European Communities L194:, 10-23. July 22, 1988.

Anon. (1993) Council Directive 93/60/EEC of 30 June 1993 amending Directive 88/407/EEC laying down the animal health requirements applicable to intra-Ccommunity trade in and imports of deep-frozen semen of domestic animals of the bovine species and extending it to cover fresh bovine semen. Official Journal of the European Communities L186:, P. 28-31. July 28, 1993.

Boelaert F, Biront P, Soumare B et al. (2000) Prevalence of bovine herpesvirus-1 in the Belgian cattle population Preventive Veterinary Medicine 45, 285-295.

Boelaert F, Speybroeck N, de Kruif A et al. (2005) Risk factors for bovine herpesvirus-1 seropositivity. Preventive Veterinary Medicine 69, 285-295.

Cameron AR, Baldock FC (1998) A new probability formula for surveys to substantiate freedom from disease. Preventive Veterinary Medicine 34, 1-17.

Castrucci G, Osburn BI, Frigeri F et al. (2000) The use of immunomodulators in the control of infectious bovine rhinotracheitis. Comparative Immunology, Microbiology and Infectious Diseases 23, 163-173.

de Ruigh L, Bosch JC, Brus MC et al. (2006) Ways to improve the biosecurity of bovine semen. Reproduction in Domestic Animals 41, 268-274.

European Food Safety Authority (2006) Definition of a BoHV-1-free animal and a BoHV-1-free holding, and the procedures to verify and maintain this status, EFSA-Q-2005-018, 2006. Annex to the EFSA Journal 311, 1-65. [Online] Available from: http://www.efsa.europa.eu/EFSA/Scientific_Opinion/ahaw_ ibr_report1,0.pdf. [Accessed 8 February 2008].

Kramps JA, Magdalena J, Quak J et al. (1994) A simple, specific, and highly sensitive blocking enzyme-linked immunosorbent assay for detection of antibodies to bovine herpesvirus-1. Journal of Clinical Microbiology 32, 2175-2181.

Kramps JA, Banks M, Beer M et al. (2004) Evaluation of tests for antibodies against bovine herpesvirus 1 performed in national reference laboratories in Europe. Veterinary Microbiology 102, 169-181.

Martin PAJ, Cameron AR, Barfod K et al. (2007a) Demonstrating freedom from disease using multiple complex data sources.
2: case study-classical swine fever in Denmark. Preventive Veterinary Medicine 79, 98-115.

Martin PAJ, Cameron AR and Greiner M (2007b) Demonstrating freedom from disease using multiple complex data sources: a new methodology based on scenario trees. Preventive Veterinary Medicine 79, 71-97.

Muylkens B, Thiry J, Kirten P et al. (2007) Bovine herpesvirus 1 infection and infectious bovine rhinotracheitis. Veterinary Research 38, 181-209.

Noordegraaf AV, Jalvingh AW, de Jong MCM et al. (2000). Evaluating control strategies for outbreaks in BHV1-free areas using stochastic and spatial simulation. Preventive Veterinary Medicine 44, 21-42.

Solis-Calderon JJ, Segura-Correa VM, Segura-Correa JC et al. (2003) Seroprevalence of and risk factors for infectious bovine rhinotracheitis in beef cattle herds of Yucatan, Mexico. Preventive Veterinary Medicine 57, 199-208.

van Schaik G, Dijkhuizen AA, Huirne RB et al. (1998) Risk factors for existence of bovine herpes virus 1 antibodies on nonvaccinating Dutch dairy farms. Preventive Veterinary Medicine 34, 125-136.

Veerkamp RF, Dillon P, Kelly E et al. (2002) Dairy cattle breeding objectives combining yield survival and calving interval for pasture-based systems in Ireland under different milk quota scenarios. Livestock Production Science 76, 137-151. 